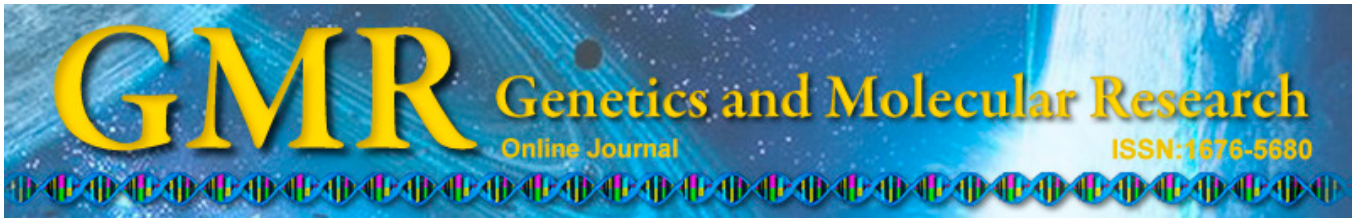

\title{
Analysis of Fcgrt gene polymorphism in indigenous Chinese sheep and its association with colostrum IgG concentration
}

\author{
Z.H. Tian ${ }^{1,2,3}$, F. Shi ${ }^{3}$, F.G. Zhong1, D.P. Bai ${ }^{1,3}$ and X.Y. Zhang ${ }^{1,2,3}$ \\ ${ }^{1}$ The Breed \& Biotechnology Key Laboratory of Sheep, \\ Xinjiang Production \& Construction Group, Shihezi, China \\ ${ }^{2}$ Key Laboratory of Tarim Animal Husbandry Science and Technology, \\ Xinjiang Production \& Construction Group, Tarim, China \\ ${ }^{3}$ College of Veterinary Medicine, Northwest A\&F University, Yangling, \\ Shaanxi, China \\ Corresponding authors: X.Y. Zhang / F.G. Zhong \\ E-mail: zhang.xy@nwsuaf.edu.cn/zfg125@sohu.com
}

Genet. Mol. Res. 14 (1): 2461-2470 (2015)

Received December 18, 2013

Accepted October 18, 2014

Published March 30, 2015

DOI http://dx.doi.org/10.4238/2015.March.30.4

\begin{abstract}
The neonatal Fc receptor ( $\mathrm{FcRn}$ ) plays an important role in regulating $\operatorname{IgG}$ homeostasis in the body and passive protection to the offspring. Changes in FcRn expression levels caused by genetic polymorphisms of Fcgrt, which encodes FcRn, may lead to interindividual differences in colostrum IgG levels in sheep. In this study, we sequenced the FcRn partial heavy chain from 179 sheep from Xinjiang Province, China, and detected the differences in colostrum IgG levels and Fcgrt genotypes to identify the correlation between the Fcgrt genotype and colostrum IgG levels in 4 sheep breeds. The DNA sequencing of a 680-bp fragment of the Fcgrt gene revealed various patterns depending on the single-strand conformation in the Suffolk breed. Sequencing analysis revealed a total of 3 patterns, $\mathrm{AA}, \mathrm{BB}, \mathrm{AB}$, in this fragment, among which the absence of $\mathrm{AB}$ and $\mathrm{BB}$ genotype acted as a marker for breed identification and characterization, while
\end{abstract}


the AA genotype was shared by Suffolk and 3 other breeds. The only allele found in all 4 breeds was allele $\mathrm{A}$, indicating that natural selection may be favoring the $\mathrm{AB}$ and $\mathrm{BB}$ genotypes in general and $\mathrm{B}$ allele in particular, as the colostrum IgG concentration was relatively higher in the Suffolk breed compared to the other 3 breeds.

Key words: Colostrum; Fcgrt; IgG; Genetic polymorphism; Sheep

\section{INTRODUCTION}

Maternal immunoglobulin ( $\mathrm{IgG})$ is transported across the neonatal intestinal epithelium within the first $24 \mathrm{~h}$ of life in lambs, which obtain maternal antibodies solely from colostrum (Besser et al., 1988a). IgG enters the blood circulation via the thoracic duct after traveling through the lymphatics (Besser et al., 1988b); the neonatal $\mathrm{Fc}$ receptor (FcRn) plays a predominant role in this process. FcRn, as a novel member of the major histocompatibility complex class I protein family, is evolutionarily distinct from all other Fc receptors (Raghavan and Bjorkman, 1996; Simister and Ahouse, 1996). FcRn was found to bind to IgG and mediate the transmission of IgG from the mother to the fetus perinatally in rodents and humans (Rodewald and Kraehenbuhl, 1984; Israel et al., 1997). It also plays a central role in the protection of serum IgG from catabolism (Junghans and Anderson, 1996). Both the conservation and bioavailability of IgG at all stages of mammalian life are attributable to FcRn (Roopenian and Akilesh, 2007; Ward and Ober, 2009).

The expression levels of FcRn directly correlate with serum IgG concentrations (Brambell et al., 1964). In murine lactating mammary glands, FcRn appears to function as a recycling receptor that transports IgG away from the milk glands (Cianga et al., 1999). In sheep, immunohistological evidence suggests that FcRn is differentially localized in mammary acinar epithelial cells before and after parturition (Mayer et al., 2002). Given the key role of FcRn in IgG and albumin homeostasis and transcytosis, and because the genotype is one of the numerous factors contributing to the failure of passive IgG transfer in sheep (Norman et al., 1981), we hypothesized that there are naturally occurring allelic variants of FcRn with functional consequences. Understanding the transcriptional regulation of the sheep Fcgrt gene and how genetic polymorphisms in the $F$ cgrt gene affect receptor expression will help identify alleles that contribute to higher colostrum IgG concentration.

\section{MATERIAL AND METHODS}

\section{Animals}

A total of 179 female sheep, comprising 4 well-known milch breeds, Chinese Merin ( $\mathrm{N}=54)$, Suffolk $(\mathrm{N}=51)$, Romney Hills $(\mathrm{N}=42)$, and BELTEX $(\mathrm{N}=32)$, were maintained at 4 different livestock farms in Xinjiang Province, China. The Chinese Merin samples were collected from the farms of the Xinjiang Production \& Construction Group, Shihezi. Suffolk samples were collected from the Key Laboratory of Tarim Animal Husbandry Science and Technology, Xinjiang Production \& Construction Group, Tarim. Romney Hills samples were collected from a rural Carla Kurt sheep farm, Carla Kurt, Xinjiang. BELTEX samples were collected from a northern Aksu sheep farm, Aksu, Xinjiang. Samples were collected randomly 
from these farms and all samples were used for Fcgrt gene polymorphism analysis and association studies of Fcgrt gene polymorphisms to determine IgG concentration in colostrum.

\section{Collection of blood samples and colostrum samples}

Approximately $2 \mathrm{~mL}$ blood was collected from the jugular vein of each animal into a sterile polypropylene vial containing 3\% EDTA. The vials were stored on ice and gel cool packs after thorough mixing and were transported to the laboratory and stored at $-20^{\circ} \mathrm{C}$ until DNA isolation. The colostrum samples of $5 \mathrm{~mL}$ were collected from the udder of each animal in a sterile polypropylene vial at $48 \mathrm{~h}$ after parturition. The vials were kept on ice and gel cool packs and were transported to the laboratory together with the blood samples and stored at $-20^{\circ} \mathrm{C}$ until $\operatorname{IgG}$ concentration measurement.

\section{Isolation of genomic DNA and colostrum IgG}

For the cloning and sequencing of sheep Fcgrt (680 bp), genomic DNA was extracted using a DNA extraction kit (Tiangen Technologies Inc., Beijing, China) from the leukocytes of blood samples. Isolated DNA samples were stored at $-20^{\circ} \mathrm{C}$ until further analysis. $\operatorname{IgG}$ in the colostrum was purified by centrifugation at 20,000 $\mathrm{g}$ for $5 \mathrm{~min}$, after adding albumen precipitation buffer solution into the colostrum and vortexing to mix for $5 \mathrm{~min}$. The supernatant was isolated into a new sterile polypropylene vial and stored at $-20^{\circ} \mathrm{C}$ for high-performance liquid chromatography (HPLC) analysis.

\section{Polymerase chain reaction (PCR) amplification of the Fcgrt gene}

A specific primer pair was designed based on the bovine $\mathrm{FcRn} \alpha$-chain sequence (Mayer et al., 2002) using the Primerprimer 5.0 software (F: GAGAGATTTGAAGCCCAAGGC; R: AGTACCTGAGCTACAATAACCTG) and standard PCR protocols. A fragment of 680 bp spanning over part of exon II, intron II, and exon III was amplified using the forward and reverse primers. PCR was performed in a $25-\mu \mathrm{L}$ reaction system using a PCR kit according to the manufacturer (reagents were purchased from Tiangen). The amplification was carried with 3 min denaturation at $94^{\circ} \mathrm{C}$, followed by 30 cycles of $30 \mathrm{~s}$ at $94^{\circ} \mathrm{C}, 30 \mathrm{~s}$ at $56^{\circ} \mathrm{C}$, and $1 \mathrm{~min}$ at $72^{\circ} \mathrm{C}$, and $5 \mathrm{~min}$ at $72^{\circ} \mathrm{C}$. The PCR was performed in a Veriti 96-well thermal cycler (Applied Biosystems, Inc., Foster City, CA, USA).

\section{Nucleotide sequence analysis of the Fcgrt gene}

Polymorphisms in Fcgrt were screened in the fragment being examined using DNA sequencing. After amplification, a $20-\mu \mathrm{L}$ sample from each PCR product was subjected to electrophoresis on a $1 \%$ agarose gel stained with ethidium bromide. The PCR products were examined with respect to a 1500-bp DNA ladder (Tiangen). The agarose gel was then scanned under UV light with Benchtop 3UV Transilluminator (Analytika Jena AG, Jena, Germany), and a single band at $680 \mathrm{bp}$ in each lane was observed and cut with a rubber-cutting knife. The bands were placed into a new sterile polypropylene vial and stored at $-20^{\circ} \mathrm{C}$ for DNA purification. PCR products were then purified using the SanPrep PCR Purification Kit (Sangon Biotech Co., Ltd., Shanghai, China) according to manufacturer protocols. The purified gene 
was inserted into a PMD19-T vector. Ligation of the Fcgrt cloning insert into the cloning site within PMD19-T was carried out by incubating $100 \mathrm{ng}(3.5 \mu \mathrm{L})$ annealed dsDNA with $0.5 \mu \mathrm{L}$ linearized vector with $5 \mathrm{U}$ T4 DNA ligase at $4^{\circ} \mathrm{C}$ overnight in $5 \mu \mathrm{L} 2 \mathrm{X}$ Rapid ligation buffer. The product was transformed into chemically competent DH-5 $\alpha$ cells (Takara, Ltd.). The cells were then plated on LB dry plates supplemented with $10 \%$ ampicillin and cultured at $37^{\circ} \mathrm{C}$ overnight, then the positive clones were selected and the plasmids were extracted using a plasmid extraction kit (Takara, Ltd.). Hybridized plasmids were tested by agarose gel by single-endonuclease digestion with BamHI, and double-endonuclease digestion with BamHI and XhoI. The plasmids were then sent to Sangon Biotech Co., Ltd., for standard double-strand DNA sequencing.

\section{Colostrum IgG concentration detection by HPLC}

IgG concentrations in the collected colostrum samples were estimated using HPLC with a 1-mL HiTrap Protein G HP column (No. 17-0404-01; GE Healthcare Bio-Sciences AB, Little Chalfont, UK). Bovine serum IgG used for calibration was reagent grade (95\% SDSPAGE) (No. I-5506, Sigma Aldrich, St. Louis, MO, USA). Bovine serum IgG for fortification was laboratory grade (No. IGGL, ICP Biotech, Auckland, New Zealand). Colostrum (1 $\mathrm{mL}$ ) was combined with an equal volume of sedimentation buffer and centrifuged at 20,000 $g$ for $5 \mathrm{~min}$. The supernatant was collected and filtered through a $0.45-\mu \mathrm{m}$ microfiltration membrane. The filtrate was collected for HPLC analysis. The gradient dilution was as follows: 0-0.5 $\mathrm{min}, 100 \%$ loading buffer, flow rate $1.0 \mathrm{~mL} / \mathrm{min}$, increase to $2 \mathrm{~mL} / \mathrm{min}$ after $1 \mathrm{~min} ; 1.0$ $1.5 \mathrm{~min}, 100 \%$ washing buffer, until $4 \mathrm{~min}$; $4-5 \mathrm{~min}$, loading buffer for $2 \mathrm{~min}$, equilibrium was reached before the next insertion, and the insertion volume was $100 \mu \mathrm{L}$.

\section{Statistical analysis}

Genotype differences among the 4 sheep breeds and individuals in each breed were analyzed using multiple sequence alignment with DNAMAN (Version 6.0). The difference in IgG concentrations in colostrum among the 4 sheep breeds was analyzed by one-way analysis of variance with the SPSS software version 13.0 (SPSS, Inc., Chicago, IL, USA).

\section{RESULTS AND DISCUSSION}

\section{DNA polymorphism analysis of the Fcgrt gene}

The DNA sequence of the 680-bp fragment of the Fcgrt gene revealed various patterns depending on the single-strand conformation in the Suffolk breed (Figure 1). Each animal in this breed exhibited a specific genotype. Sequencing analysis revealed a total of 3 patterns, $\mathrm{AA}, \mathrm{BB}, \mathrm{AB}$, in this fragment with 2 alleles, $\mathrm{A}$ and $\mathrm{B}$. Among these genotypes, the absence of the $\mathrm{AB}$ and $\mathrm{BB}$ genotype was used as a marker for breed identification and characterization, while the AA genotype was shared by Suffolk and the other 3 breeds, including Chinese Merin, Romney Hills, and BELTEX (Figure 2). The only allele found in all 4 breeds was the A allele, indicating that natural selection may be favoring the $\mathrm{AB}$ and $\mathrm{BB}$ genotypes in general and $\mathrm{B}$ allele in particular, as the colostrum IgG concentration was relatively higher in the Suffolk breed compared to the other 3 breeds. Because there is a lack 
of related genotype polymorphism information in the literature, these findings could not be validated using previous studies.
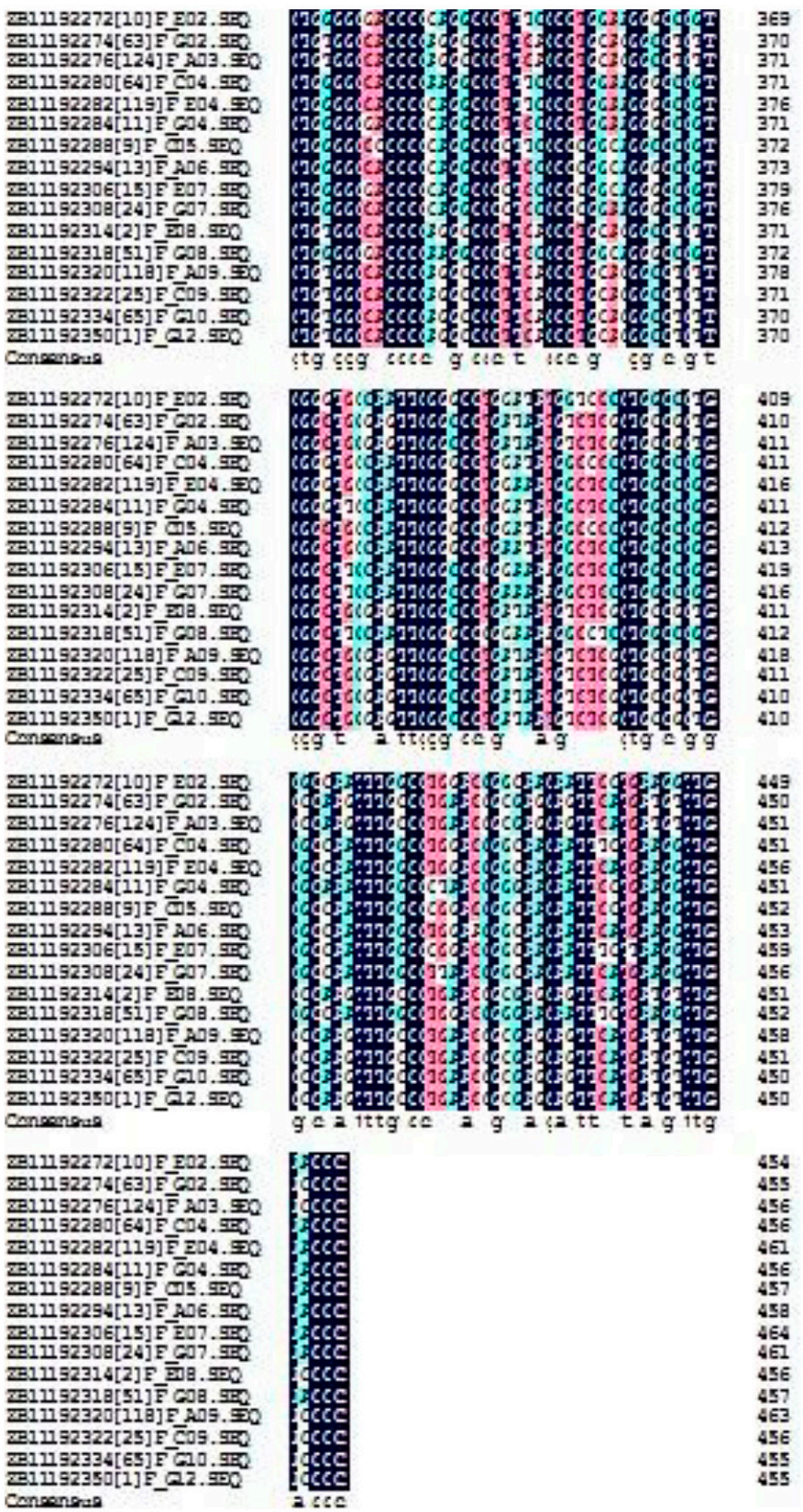

454
455
456
456
451
456
457
458
464
411
456
457
453
456
455
455

Figure 1. Sequence BLAST results of Suffolk sheep (partial). 


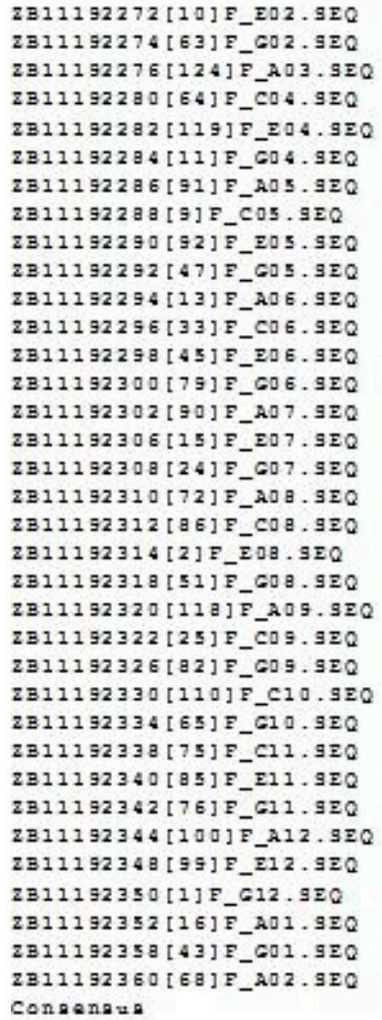

Figure 2. Sequence BLAST result of 4 sheep breeds (partial).

For the other species, there was a sufficient number of polymorphisms in the Fcgrt gene in the various breeds of sow and dairy cows for examination. Laegreid et al. (2002) investigated the allelic variation of Fcgrt and its association with variation of IgG concentration in neonatal calves, and 5 single-nucleotide polymorphisms were identified by sequencing 1305 bp of the Fcgrt genomic DNA from a multi-breed panel of 96 cattle and 27 founders of a reference population. Clawson (2004) evaluated haplotypes associated with high or low serum IgG levels in newborn calves. Eight haplotypes were identified by sequencing regions of B2M exons II and IV in a multi-breed panel of 96 beef cattle. Calves homozygous for 1 of the 8 haplotypes (B2M 2.2) were at increased risk of failure of passive IgG transfer. However, Freiberger et al. (2010) found no association between the FcRn promoter polymorphism, both maternal FcRn and of fetal FcRn, and the rate of maternal-fetal IgG transfer by analyzing 103 single fetal samples and 103 paired maternal and fetal samples collected from the umbilical cord blood of full-term neonates.

\section{Colostrum IgG concentration in Suffolk, Chinese Merin, Romney Hills, and BELTEX sheep}

For many mammals, the young offspring obtain passive immunity from the colos- 
trum; IgG plays a dominant role in this immunoprotective action, with a concentration as high as $101 \mathrm{mg} / \mathrm{mL}$ in sheep colostrum. We found that the BB genotype had the highest average $(105 \mathrm{mg} / \mathrm{mL}) \mathrm{IgG}$ concentration, while the AA genotype had the lowest average $(85 \mathrm{mg} / \mathrm{mL})$ $\mathrm{IgG}$ concentration. IgG concentration is an index of the FcRn expression level and reflects the status of IgG transport (mainly FcRn-mediated) system in the body. These results may have been observed because of the different sample collection periods used. Differences in the colostrum IgG concentration were statistically significant among the various genotypes.

Total IgG colostrum levels and the ratios of IgG content $>10 \% /$ total samples tested are shown in Figures 3 and 4. The intervarietal differences in total colostrum IgG concentrations were not significant among the 4 breeds $(\mathrm{P}>0.5$; Figure 3$)$, while the differences in the ratios of IgG content $>10 \% /$ total samples tested are significant $(\mathrm{P}<0.0001$; Figure 4$)$. The colostrum IgG concentration variety within 1 breed ranged from $19.36-3.05 \%$ in Chinese Merin, $21.94-2.64 \%$ in Suffolk, 20.64-0.73\% in Romney Hills, and $21.63-3.27 \%$ in BELTEX. This interclass significance can be partially explained by individual differences; however, other factors should be further explored.

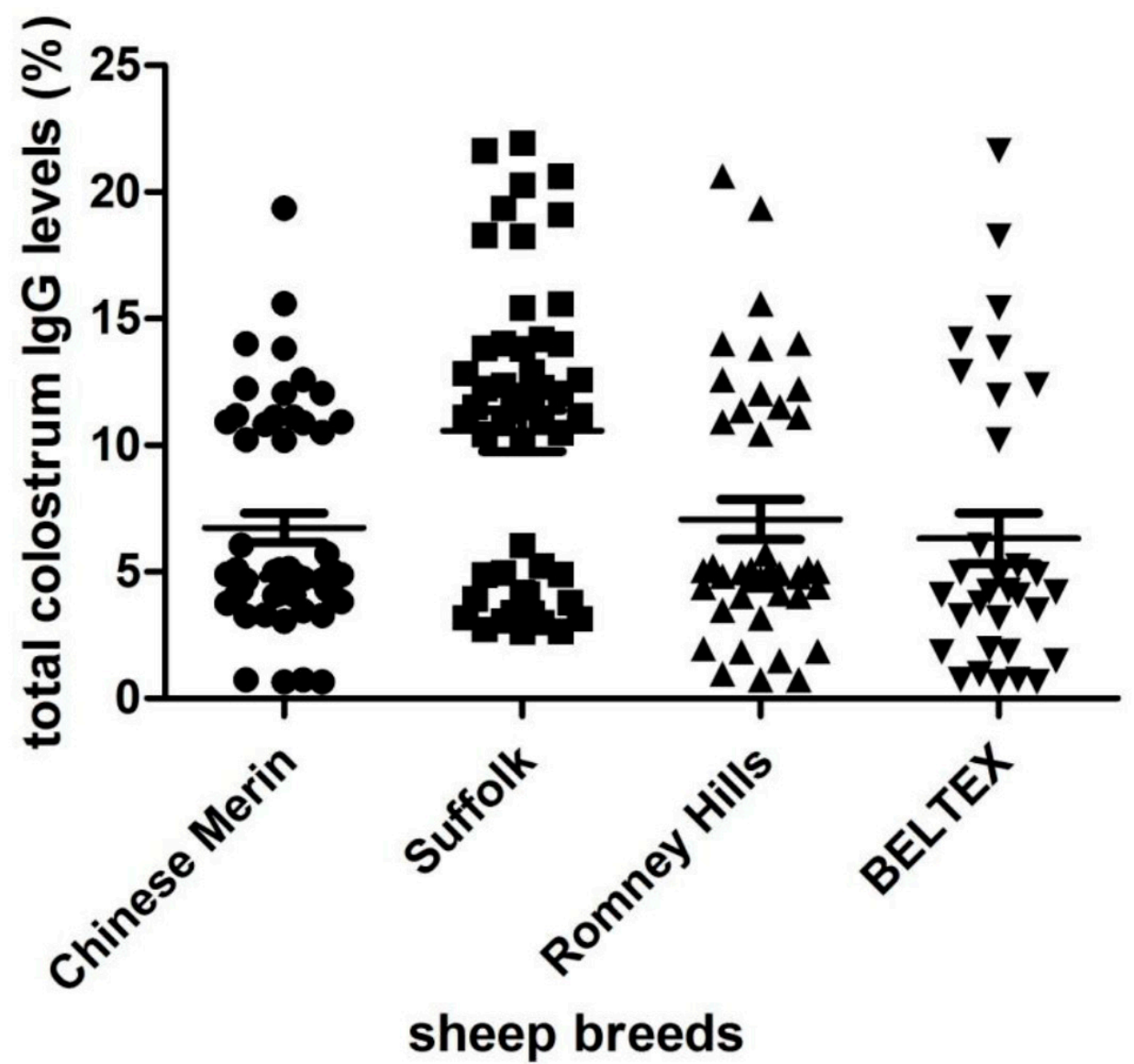

Figure 3. IgG contents in the colostrum of Suffolk, Romney Hills, BELTEX, and Chinese Merin. 


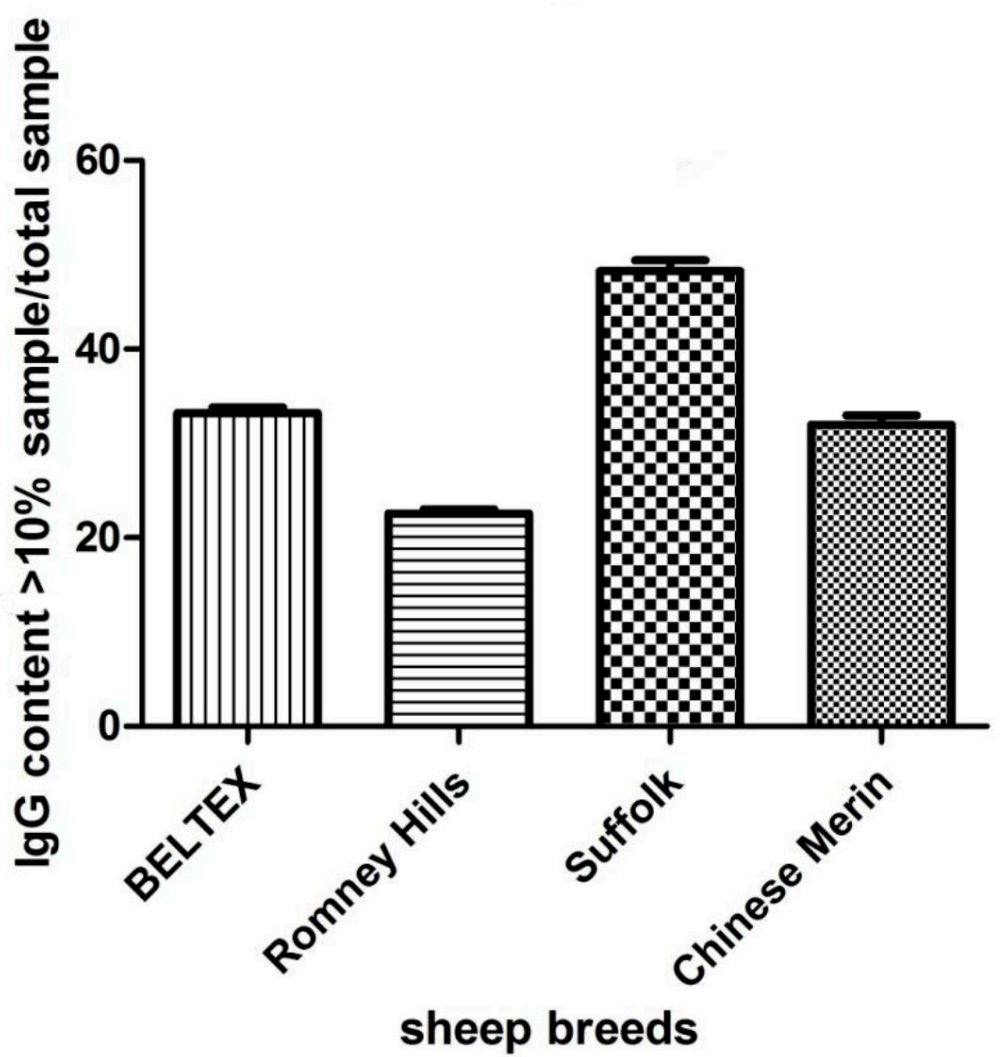

Figure 4. Differences among breeds in samples of IgG relative content $>10 \%$.

\section{Nucleotide sequence analysis}

Various alleles of the 680-bp fragment of the Fcgrt gene were sequenced using Sanger's dideoxy chain termination sequencing method. The sequences obtained were compared with other available sequences from sheep (Accession No. Q8HZV2), and the amplified fragment was confirmed to include exon II, intron II, and exon III. All sequences were aligned using Multiple Sequence BLAST program of the DNAMAN software using Accession No. Q8HZV2 as the corresponding sequence (Figure 1 shows partial data). Based on the alignment of the allelic variants, there are differences in 23 positions among the alleles, of which maximum variations (at 13 locations) were found in the exon II region in contrast to 4 variations in the exon III region. As there is no genotype information available regarding sheep Fcgrt's intronic region, various substitutions in the Fcgrt intron II region observed in this study werenot analyzed.

\section{CONCLUSIONS}

In mammals, FcRn has prominent maternal and neonatal roles in IgG transfer (Ghetie and Ward, 2000). Among the 4 breeds examined, numerous mutations existed in the Fcgrt se- 
quence in Suffolk (Figure 1) compared to individuals within the breed and across the breeds, while the other 3 breeds showed few mutations in the genes tested (Figure 2). A possible explanation for this observation is that the Suffolk breed is mainly raised for wool and meat purposes in this area, and its members were crossed with the progeny of other mountain ewes, whereas the other 3 breeds were pure. It is common to have more mutations in a crossbreed compared to pure breeds, even within the same gene.

The presence or absence of a particular genotype observed in this study can be utilized as a marker for breed identification. No significant effect of genotypes was observed on colostrum IgG concentration, although there were some significant differences among the mean values. This may be because the 680-bp fragment of the Fcgrt gene may contribute in part to the total variation present. The change in the amino acid sequence of FcRn may influence its binding affinity with $\operatorname{IgG}$, thus influencing the transportation effect of maternal $\operatorname{IgG}$ into colostrum.

\section{ACKNOWLEDGMENTS}

Research supported by the Open Foundation of the Provincial Department of the State Key Laboratory of Constructing Cultivating Base (\#2011KLS07), the Key Biotechnology Laboratory of Xinjiang corps sheep breeding; the Open Foundation of the Provincial Department of the State Key Laboratory of Tarim Animal Husbandry Science and Technology (\#HS201305), Xinjiang Production \& Construction group; Corps of Germplasm Innovation, Excavation and Utilization of Functional Genes (\#2012BB044); and the Scientific Research Foundation for the Returned Overseas Chinese Scholars (\#K308021101).

\section{REFERENCES}

Besser TE, Gay CC, McGuire TC and Evermann JF (1988a). Passive immunity to bovine rotavirus infection associated with transfer of serum antibody into the intestinal lumen. J. Virol. 62: 2238-2242.

Besser TE, McGuire TC, Gay CC and Pritchett LC (1988b). Transfer of functional immunoglobulin G (IgG) antibody into the gastrointestinal tract accounts for IgG clearance in calves. J. Virol. 62: 2234-2237.

Brambell FW, Hemmings A and Morris IG (1964). A theoretical model of gamma globulin catabolism. Nature 203: $1352-1355$.

Cianga P, Medesan C, Richardson JA, Ghetie V, et al. (1999). Identification and function of neonatal Fc receptor in mammary gland of lactating mice. Eur. J. Immunol. 29: 2515-2523.

Clawson ML, Heaton MP, Chitko-McKown CG, Fox JM, et al. (2004). Beta-2-microglobulin haplotypes in U.S. beef cattle and association with failure of passive transfer in newborn calves. Mamm. Genome 15: 227-236.

Freiberger T, Ravcuková B, Grodecká L, Krecová B, et al. (2010). No association of FCRN promoter VNRT polymorphism with the rate of maternal-fetal IgG transfer. J. Reprod. Immunol. 85: 193-197.

Ghetie V and Ward ES (2000). Multiple roles for the major histocompatibility complex class I-related receptor FcRn. Ann. Rev. Immunol. 18: 739-766.

Israel EJ, Taylor S, Wu Z, Mizoguchi E, et al. (1997). Expression of the neonatal Fc receptor, FcRn, on human intestinal epithelial cells. Immunology 92: 69-74.

Junghans RP and Anderson CL (1996). The protection receptor for IgG catabolism is the b2-microglobulin-containing neonatal intestinal transport receptor. Proc. Natl. Acad. Sci. U S A 93: 5512-5516.

Laegreid WW, Heaton MP, Keen JE, Grosse WM, et al. (2002). Association of bovine neonatal Fc receptor alpha-chain gene (FCGRT) haplotypes with serum IgG concentration in newborn calves. Mamm. Genome 13: 704-710.

Mayer B, Zolnai A, Frenyo LV, Jancsik V, et al. (2002). Redistribution of the sheep neonatal Fc receptor in the mammary gland around the time of parturition in ewes and its localization in the small intestine of neonatal lambs. Immunology 107: 288-296. 
Norman LM, Hohenboken WD and Kelley KW (1981). Genetic differences in concentration of immunoglobulins G1 and $\mathrm{M}$ in serum and colostrum of cows and in serum of neonatal calves. J. Anim. Sci. 53: 1465-1472.

Raghavan M and Bjorkman PJ (1996). Fc receptors and their interactions with immunoglobulins. Annu. Rev. Cell. Dev. Biol. 12: 181-220.

Rodewald R and Kraehenbuhl JP (1984). Receptor-mediated transport of IgG. J. Cell. Biol. 99: 159s-164s.

Roopenian DC and Akilesh S (2007). FcRn: the neonatal Fc receptor comes of age. Nat. Rev. Immunol. 7: 715-725.

Simister NE and Ahouse JC (1996). The structure and evolution of FcRn. Res. Immunol. 147: 333-337.

Ward ES and Ober RJ (2009). Chapter 4: multitasking by exploitation of intracellular transport functions the many faces of FcRn. Adv. Immunol. 103: 77-115. 